Pereira, M. A.; Campos, W. G. Pagamento por serviços ambientais aliando conservação e Ecoturismo.

Revista Brasileira de Ecoturismo, São Paulo, v.2, n.3, 2009, pp.255-272.

\title{
Pagamento por Serviços Ambientais aliando Conservação e Ecoturismo ${ }^{1}$
}

\author{
Marco Aurélio Pereira, Wildes Gomes de Campos
}

\section{RESUMO}

A região de Itacaré, no sul da Bahia possui grande parte das suas trilhas, praias, lagoas e rios situados na Área de Proteção Ambiental (APA) Itacaré Serra Grande. Nessa região encontram-se inúmeras pequenas propriedades rurais que perderam sua vocação agrícola com a crise cacaueira nos anos de 1990 e com as restrições consequentes da instituição da APA. Tais propriedades abrigam florestas de grande biodiversidade, que precisam ser preservadas das ações de caçadores, de extrações ilegais de madeira e dos impactos negativos de um turismo predatório. O trabalho de campo desenvolvido neste estudo objetivou realizar um diagnóstico para avaliar a possibilidade da criação de um fundo para Pagamento de Serviços Ambientais (PSA) tendo o trade turístico como potencial doador e pequenos proprietários rurais vinculados a projetos socioambientais já em desenvolvimento, como beneficiários do mecanismo de pagamento. Foram entrevistados proprietários rurais para calcular a renda agrária de cada propriedade e verificar o custo de oportunidade do uso da terra. A partir do custo de oportunidade seria possível estabelecer o valor do pagamento e o montante necessário para a composição do fundo. Com a finalidade de identificar a disponibilidade dos empreendedores locais a contribuir com o fundo, foram aplicados questionários de Valoração Contingente aos empreendedores turísticos locais. Tais questionários continham três tipos de questões: abertas, para ordenação (ranking) e de alternativas. $\mathrm{Na}$ intenção de articular a necessidade de manter a riqueza biológica, o potencial turístico da região e melhorar a qualidade de vida dos proprietários rurais, este trabalho analisou, também, a disponibilidade de contribuição dos turistas e do trade turístico da região para a implantação do projeto de PSA. Conclui-se que, é viável a implementação de um fundo para pagamento de serviços ambientais devido a disponibilidade para contribuição por parte dos empreendedores e turistas. No entanto, como hipótese derivada do estudo, entendese que este mecanismo não é suficiente para garantir a sustentabilidade ambiental da região, necessitando de ações complementares com o desenvolvimento de políticas públicas voltadas para o setor.

PALAVRAS-CHAVE: Ecoturismo, Conservação Ambiental, Pagamento por Serviços ambientais. 


\section{Payments for environmental services combining conservation and Ecotourism}

\section{ABSTRACT}

The region of Itacaré, located in the Southern of the State of Bahia in Brazil is very well known for its natural resources such as beaches, lakes, rivers and open trails and belongs to the Itacaré Serra Grande Environmental Protection Area «Área de Proteção Ambiental (APA)». Within the area several private rural properties exist, mainly of small size. Most of those properties were traditionally adapted to the production of cocoa beans for centuries which during the 90's had its failure due to natural causes. Since then, the designation of that (APA) did not aid the farmers either. The regions encompass very valuable forests and biodiversity which do need protection from illegal extractivism, hunters and predatory tourism. The objective of the this field research is to effectively draw a diagnostic of the present situation with the purpose of launching a possible leveraging fund which would assist the locals with payment for environmental services (PES). The funding would originate from the private local tourism sector and benefit the local on going environmental projects. Interviews were taken with landowners in order to figure out the land rental value of each property and in order to determine the opportunity cost of land usage. Once that data was gathered it became possible to establish the reasonable amount of payments and the size the funding should be composed of. In order to find out the local entrepreneurs capacity to compose such funding the researchers applied Contingent Valuation Questionnaires. There were three kinds of questions: open, ranking and alternatives. The research intended to articulate between the need to preserve the natural biological assets of the region, the measurement of its tourism trade potential and the viability of improvement on the quality of life of local landowners. The work also contemplated the availability of funding from tourists and tourism operators in that region in order to compose the PES fund. The research concluded it is possible to implement a fund for Payment of Environmental Services counting of the support of local entrepreneurs and the tourism sector, however, the research also indicates that such fund leveraging mechanism is not sufficient to ensure the sustainability of the region. It would require complementary action from the public sector by means of creating and implementing supporting policies.

KEY-WORDS: Ecotourism, Environmental Conservation, Payment for Environmental Services.

\section{INTRODUÇÃO}

\section{O Ecoturismo e a conservação dos recursos naturais}

Economicamente, o turismo é hoje a mais lucrativa das atividades civis, sendo o Ecoturismo responsável por $7 \%$ do total do lucro obtido pelas atividades turísticas no Brasil (PADUA et al., 2001). Segundo as Diretrizes para uma Política Nacional de Ecoturismo (BRASIL, 1994, p. 2). 
O Ecoturismo é um segmento da atividade turística que utiliza, de forma sustentável, o patrimônio natural e cultural, incentiva sua conservação e busca a formação de uma consciência ambientalista através da interpretação do meio ambiente, promovendo o bem-estar das populações.

No Brasil, o Ecoturismo engloba a proteção ambiental, trocas culturais e geração de renda e emprego (LAYRARGUES, 2004). A atividade é vista como uma forma de curar as chagas da desigualdade social, uma vez que movimenta cifras gigantescas, cerca de quinhentos milhões de reais por ano, com visitação aproximada de meio milhão de turistas por ano. É o segmento com crescimento mais expressivo em todo o mundo, impulsionado pelo resgate de valores sociais, em que a natureza deixa de ser vista como objeto de exploração e passa a ser encarada pelo seu valor de existência por muitos viajantes, consequência da crescente escassez dos recursos naturais (LAYRARGUES, 2004; PADUA et al., 2001).

Mas infelizmente algumas experiências desse setor têm enfocado apenas o lucro, trazendo prejuízos para o meio ambiente. Ironicamente, os países que detêm os maiores índices de biodiversidade do planeta, também se destacam pela pobreza e miséria, que causam pressões aos recursos naturais existentes, sendo assim necessária a elaboração de modelos alternativos de desenvolvimento e conservação que contemplem essas regiões (PADUA et al., 2001).

Segundo Jesus (2003, apud NEIMAN, 2007) o Ecoturismo que inicialmente propunha alternativas turísticas pautadas na conservação ecológica, tornou-se um turismo predatório, utilizando-se de estratégias de marketing com discursos ecológicos, nem sempre praticados. Somente quando o Ecoturismo realmente incorporar a ética ambiental, juntamente com o respeito às culturas tradicionais, poderá ter impacto positivo, sendo fonte de renda para locais que ainda têm natureza preservada (PADUA et al., 2001)

O Ecoturismo deveria ser visto como uma forma de proteção ambiental, com ênfase nas análises de capacidade de suporte, ou seja, o número ideal de visitantes que não cause impactos ecologicamente negativos, havendo um equilíbrio entre os aspectos econômico e ecológico. Se o fator econômico não se sobrepusesse aos demais fatores do Ecoturismo, com certeza esta atividade seria uma excelente estratégia para a proteção do patrimônio ambiental e cultural das regiões, pois poderia aproximar o turista dos elementos naturais (LAYRARGUES, 2004). De acordo com Neiman (2007), o Ecoturismo é uma das ferramentas de Educação Ambiental que precisa ser mais bem estruturada, já que nos últimos anos configurou-se como atividade economicamente viável.

Diante dos impactos negativos causados pela visitação de massa, práticas de Educação Ambiental se transformam em veículo do Ecoturismo, sendo vistas como uma forma de garantir a sustentabilidade do empreendimento. Assim, a Educação Ambiental torna-se primordial para articular os mecanismos relacionados ao Ecoturismo, inclusive envolvendo e sensibilizando os turistas, no que se refere à proteção ambiental e cultural dos espaços visitados (LAYRARGUES, 2004). 
Para Rasteiro (2002, apud NEIMAN, 2007, p. 47):

Em diversos encontros nacionais e internacionais sobre o tema tem sido evidente o grau de distorção sobre o que vem a ser Ecoturismo, mas não há como se pensar em outro que não envolva três pontos básicos: planejamento sustentável, Educação Ambiental e inclusão social.

Layrargues (2004) comenta a necessidade da criação de políticas públicas que tenham caráter socialmente justo no tocante à distribuição dos recursos gerados pelo Ecoturismo, contemplando inclusive não só os aspectos ambientais e culturais, mas também os socioeconômicos da sustentabilidade. O autor afirma que os modelos ecoturísticos vigentes hoje apresentam dois eixos: o Ecoturismo de base comunitária e o Ecoturismo empreendedor (Tabela 1).

Tabela 1 - Modelos de Ecoturismo, segundo Layrargues (2004).

\begin{tabular}{|c|c|}
\hline Ecoturismo de base comunitária & Ecoturismo empreendedor \\
\hline $\begin{array}{l}\text { A comunidade local é a própria operado- } \\
\text { ra do negócio ecoturístico, permitindo o } \\
\text { desenvolvimento comunitário local, a e- } \\
\text { mancipação política e favorecendo a dis- } \\
\text { tribuição de renda. }\end{array}$ & $\begin{array}{l}\text { A operadora do negócio ecoturístico não } \\
\text { é proveniente da comunidade local, mas } \\
\text { de centros urbanos, o que dificulta a dis- } \\
\text { tribuição de renda. }\end{array}$ \\
\hline $\begin{array}{l}\text { A renda gerada permanece na comunida- } \\
\text { de local e é distribuída entre os trabalha- } \\
\text { dores da atividade. }\end{array}$ & $\begin{array}{l}\text { A renda gerada é destinada ao lucro dos } \\
\text { empreendedores que financiam a ativida- } \\
\text { de. }\end{array}$ \\
\hline $\begin{array}{l}\text { Há espaço para inclusão e inclusive as- } \\
\text { censão social, já que a própria comunida- } \\
\text { de local é responsável pela gestão da } \\
\text { atividade. }\end{array}$ & $\begin{array}{l}\text { Fala-se de oportunidade de geração de } \\
\text { emprego para a comunidade local, para } \\
\text { ocupar funções de serviços, mas não de } \\
\text { empreendimento. }\end{array}$ \\
\hline $\begin{array}{l}\text { O pacote ecoturístico envolve múltiplas } \\
\text { dimensões: natureza, história e cultura } \\
\text { como variáveis indissociadas. Locais de } \\
\text { destino são sobretudo comunidades ex- } \\
\text { trativistas. }\end{array}$ & $\begin{array}{l}\text { O pacote ecoturístico privilegia a beleza } \\
\text { natural. Locais de destino são sobretudo } \\
\text { os 'hotéis de selva'. }\end{array}$ \\
\hline $\begin{array}{l}\text { O turista imerge na realidade local real, } \\
\text { se impregna da vida cotidiana da coletivi- } \\
\text { dade, vivencia o envolvimento profundo e } \\
\text { legítimo da rotina da comunidade local } \\
\text { naquele espaço protegido. O turista ex- } \\
\text { perimenta a alteridade de si com o outro } \\
\text { como continuidade da natureza. }\end{array}$ & $\begin{array}{l}\text { O turista imerge numa realidade fantasio- } \\
\text { sa, vivencia um contato idealizado de u- } \\
\text { ma natureza idílica, virgem e dadivosa, } \\
\text { de forma superficial e } \\
\text { folclórica. O turista experimenta apenas a } \\
\text { alteridade de si com a natureza exposta } \\
\text { numa vitrine. }\end{array}$ \\
\hline $\begin{array}{l}\text { O turista experimenta um contato direto } \\
\text { com a realidade, com pouca mediação } \\
\text { do guia. }\end{array}$ & $\begin{array}{l}\text { O turista experimenta um contato indireto } \\
\text { com a realidade, com forte mediação do } \\
\text { guia. }\end{array}$ \\
\hline
\end{tabular}




\section{A Área de Proteção Ambiental (APA) Itacaré Serra Grande e sua realidade}

A região Sul da Bahia, onde está localizada a Área de Proteção Ambiental (APA) Itacaré Serra Grande é a mais rica em biodiversidade do planeta, chegando a apresentar 270 espécies em um único hectare (DEAN, 1996). A excepcional biodiversidade da região e a paisagem costeira ainda bastante preservada (Figura 1) são fundamentais atrativos turísticos que movimentam a economia local (IFV, 2008). De acordo com o Sistema Nacional de Unidades de Conservação - SNUC (BRASIL, 2000), uma Área de Proteção Ambiental (APA)

é uma área em geral extensa, com um certo grau de ocupação humana, dotada de atributos abióticos, bióticos, estéticos ou culturais especialmente importantes para a qualidade de vida e o bem-estar das populações humanas, e tem como objetivos básicos proteger a diversidade biológica, disciplinar o processo de ocupação e assegurar a sustentabilidade do uso dos recursos naturais (art. 15).

A APA Itacaré Serra Grande foi criada em 1993 devido à necessidade de proteger uma extensa área litorânea, composta por planícies costeiras, cordões arenosos formando restinga, associado a remanescentes bem preservados da Mata Atlântica, além de áreas estuarinas e manguezais de grande diversidade biológica, grande potencial turístico e beleza ímpar (IFV, 2004).

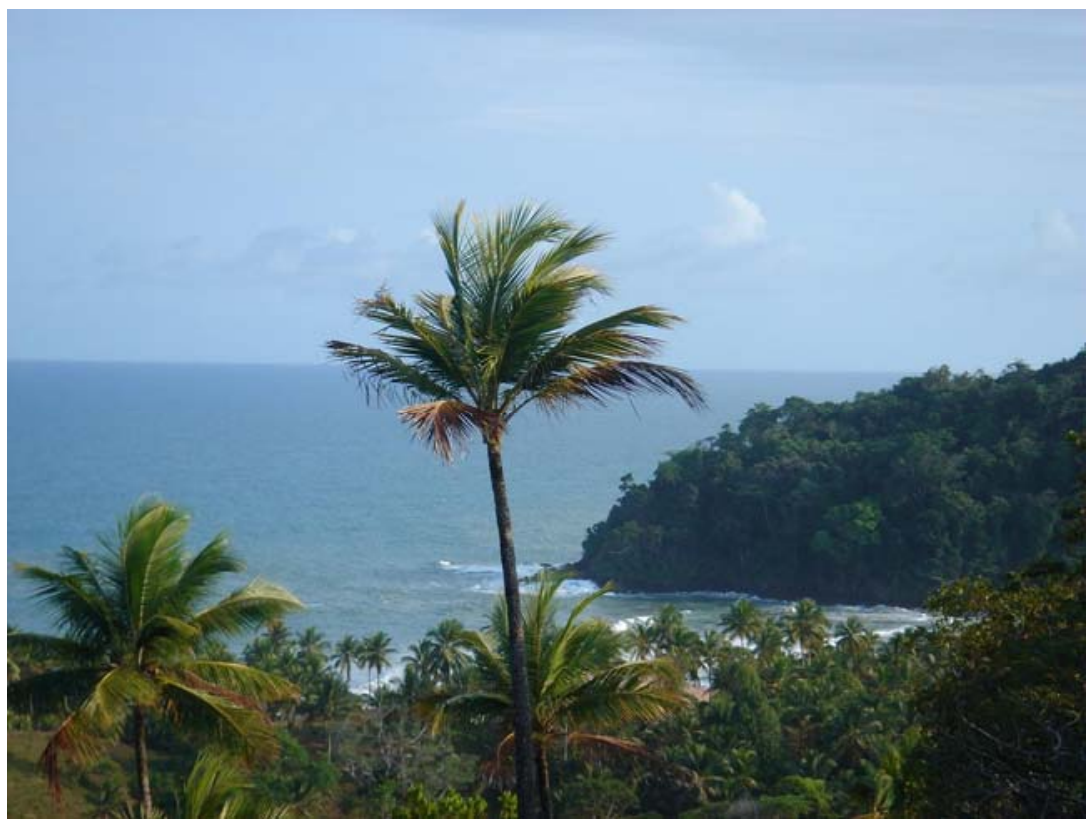

Figura 1 - Paisagem litorânea da APA Itacaré Serra Grande (BA). Foto: Wildes Gomes de Campos.

O sistema agroflorestal cabruca, tradicional na região, que se caracteriza pelo plantio de cacau junto à floresta nativa, é um importante conector de paisagens, mas 
tem sido convertido em atividades agropecuárias e atividades voltadas para o turismo, o qual potencializou a exploração imobiliária. A crise da lavoura cacaueira provocou um alto índice de migração da população rural para os centros urbanos, intensificado com as restrições no uso da terra, advindas com a criação do Parque Estadual da Serra do Condurú e da APA Itacaré Serra Grande. Apesar da mudança da estrutura econômica da região, potencializada pelo turismo, a APA mantém ainda cerca de $70 \%$ do seu território ocupado por florestas e sistemas agroflorestais associados ao cacau.

As atividades de exploração ilegal de madeira nos fragmentos de matas ainda preservadas constituem forte ameaça ao ecossistema de Mata Atlântica presente nesta área. A pavimentação da Rodovia BA 001, trecho Ilhéus-Itacaré, representou outra grande influência negativa na conservação da região, antes protegida pela dificuldade de acesso. Em consequência disso, a região passou a atrair um grande número de pessoas e empreendimentos, provocando aumento da demanda por terras, por produtos madeireiros e agrícolas, áreas para urbanização, serviços de saneamento, obras de infraestrutura, dentre outros.

Estas demandas passaram a pressionar fortemente os recursos naturais, que constituem o principal atrativo turístico da região de Itacaré, com suas belíssimas paisagens e grande diversidade biológica (IFV, 2004). A melhoria de vida das comunidades rurais e urbanas da região e a conservação da natureza dependem de uma integração econômica com a atividade turística sustentável.

Na APA Itacaré Serra Grande, o panorama da desigualdade social não é diferente do seu entorno mais abrangente. Lá o turismo vem crescendo a cada ano, gerando recursos financeiros aos empreendedores turísticos, que, em sua maioria, são oriundos de outras regiões do Brasil ou do exterior. Aos moradores locais são destinados normalmente, os serviços menos qualificados. Além disso, a falta de planejamento tem provocado degradação ambiental por desordenamento na construção dos empreendimentos, acúmulo de lixo e uso exaustivo dos recursos naturais.

Para se consolidar como destino ecoturístico, a região de Itacaré Serra Grande, necessariamente precisaria implementar estratégias de gerenciamento que respeitassem as condições naturais e as comunidades locais, estabelecendo um envolvimento econômico efetivo, que favoreça a melhoria da qualidade de vida dessas populações. Padua et al. (2001) entendem que o Ecoturismo é sem sombra de dúvidas uma alternativa que possibilita aliar desenvolvimento com conservação, mas para que isso ocorra se faz necessário considerar as ameaças aos ecossistemas e às estruturas sociais onde é desenvolvido.

Diante desse quadro, discutem-se medidas que viabilizem a mitigação dos problemas ambientais da região, de forma que se possa aliar esforços junto ao trade turístico (turistas e empreendedores turísticos locais), analisando a viabilidade da elaboração de um sistema de pagamentos por serviços ambientais que contribua com a conservação ecológica do Sul da Bahia.

Apenas um turismo em sintonia com as comunidades e com a conservação do meio ambiente, fará com que o turista incorpore esse aprendizado para sua vida, gerando sensibilização para a preservação da natureza e do patrimônio cultural.

No entanto, na região sul da Bahia, o que tem ocorrido é o que Layrargues 
(2004) denomina de Ecoturismo Empreendedor. De acordo com Vasques (2005), o município de Itacaré recebe 80 mil visitantes por ano.

\section{Serviços ambientais e conservação florestal}

Segundo Wunder (2008), o Pagamento por Serviços Ambientais (PSA) implica em uma transação voluntária entre algum comprador e o provedor de um serviço ambiental ou uma forma de uso da terra que possa assegurar esse serviço. Ou seja, consiste em pagar o produtor rural, responsável pelos serviços ambientais prestados à comunidade, para compensar uma perda econômica ocasionada pela manutenção desses serviços. Assim, além de um instrumento econômico, o PSA constitui-se como mecanismo de política ambiental ao incentivar práticas conservacionistas, sem impedir práticas produtivas (MICOL et al., 2008). Com a conservação de áreas florestais, a sociedade como um todo beneficia-se pelos serviços ecossistêmicos, que são os benefícios diretos e indiretos oriundos dos ecossistemas, como por exemplo, a provisão de alimentos, a regulação climática e a formação do solo (De GROOT et al., 2002).

Os municípios que hospedam a APA Itacaré Serra Grande contam com presença de agricultores familiares detentores de florestas naturais. Três comunidades rurais - Serra Grande, Taboquinhas e Marambaia, que foram foco dessa pesquisa - são fundamentais para a conservação da natureza local, por estarem ao longo da rodovia Ilhéus Itacaré e abrigarem parte importante das pequenas bacias hidrográficas que alcançam as praias deste litoral, com rios e riachos bastante preservados. Sendo tais áreas de grande interesse para o turismo local, o pagamento por serviços ecossistêmicos pode estar relacionado com a beleza cênica e a conservação da biodiversidade. A Figura 2 apresenta o uso e ocupação do solo na região, onde se observa áreas de florestas circundadas por áreas de agricultura e pecuária, mas ainda em conectividade. Se não houver um incentivo aos agricultores locais para manutenção da vegetação natural, corre-se o risco das áreas de produção avançarem e restarem pequenos fragmentos florestais com grande perda de biodiversidade.

Esforços para a conservação e manutenção dessas áreas justificam-se pela extraordinária riqueza natural e por garantir a eficiência dos inúmeros serviços ambientais como a captura e armazenamento de carbono e a manutenção de mananciais, que favorecem a integridade dos solos pelos processos hidrológicos contemplando o bem-estar humano, bem como a manutenção de recursos econômicos para a população local.

De acordo com a Ecotourism Society International, o Ecoturismo pode ser encarado como uma das formas de "turismo responsável para áreas naturais, que conserva o meio ambiente e dá sustentação ao bem-estar das populações locais" (apud PADUA et al., 2001, p.28). Estratégia que possibilita o reinvestimento do recurso local arrecadado viabilizando a conservação dos ecossistemas envolvidos. 


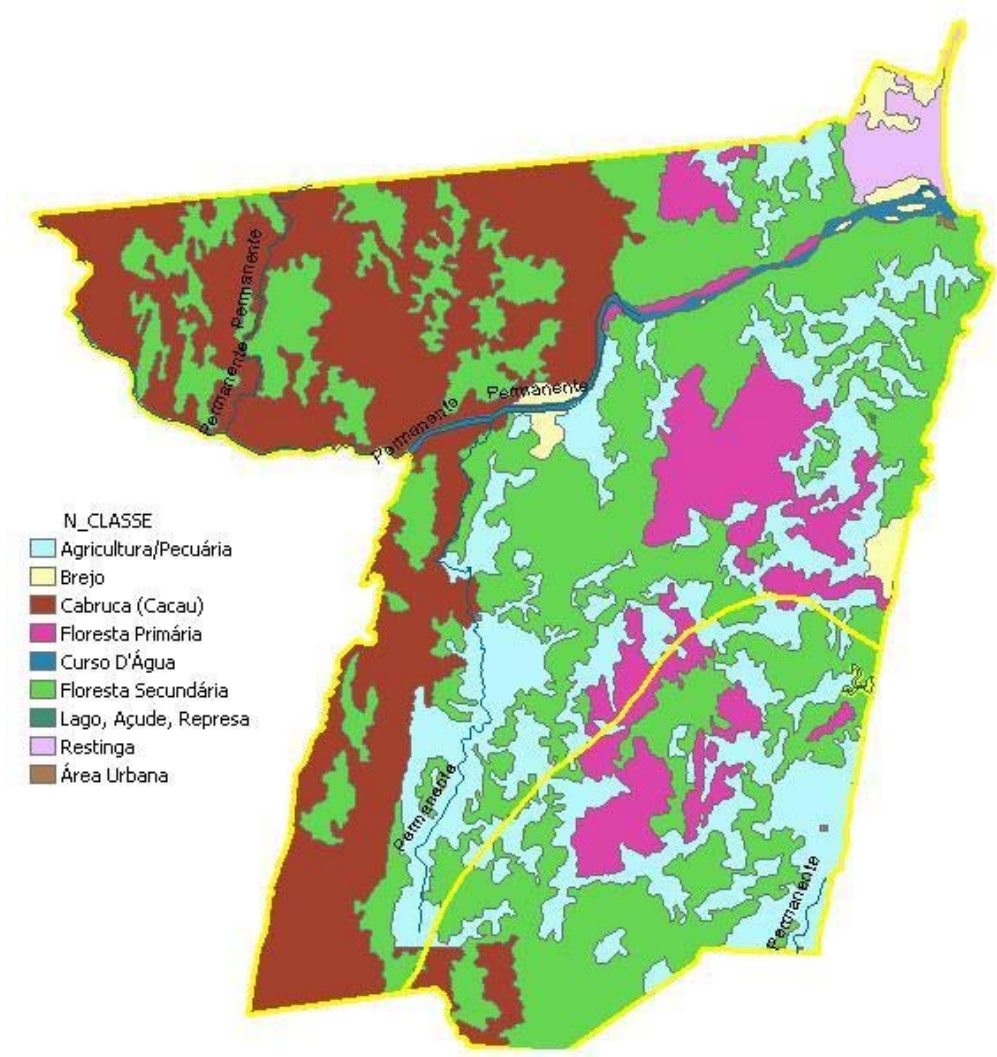

Figura 2 - Mapa do uso e ocupação do solo na APA Itacaré Serra Grande (BA).

Fonte: Laboratório de análise ambiental - Instituto Floresta Viva, disponibilizado por Danusa Campos.

Diante desse quadro, o presente trabalho objetiva analisar se há disponibilidade dos turistas e do trade turístico da região de Itacaré para contribuir com o fundo para pagamento por serviços ambientais disponíveis, condicionado ao comprometimento dos proprietários rurais (Figura 3) a desenvolver atividades que garantam a conservação da área florestal através de práticas sustentáveis.

Especificamente pretendeu-se:

- Verificar a viabilidade econômica da implementação de uma taxa para a conservação ambiental na região;

- Verificar a disponibilidade de empreendedores e turistas para participar do mecanismo, como potenciais doadores;

- Estabelecer valores que possam ser coerentemente aplicáveis para a participação dos empreendedores e turistas.

A criação de um fundo para pagamentos de serviços ambientais na região poderá: 1) estimular o manejo adequado dos recursos naturais protegendo a cobertura florestal, a biodiversidade e os recursos hídricos da região; 2) favorecer o incremento de renda aos proprietários rurais; 3) favorecer a continuidade de programas agroflores- 
tais e de econegócios, iniciados por instituições sociais da região; 4) fomentar ações de educação ambiental no desenvolvimento do Ecoturismo local.

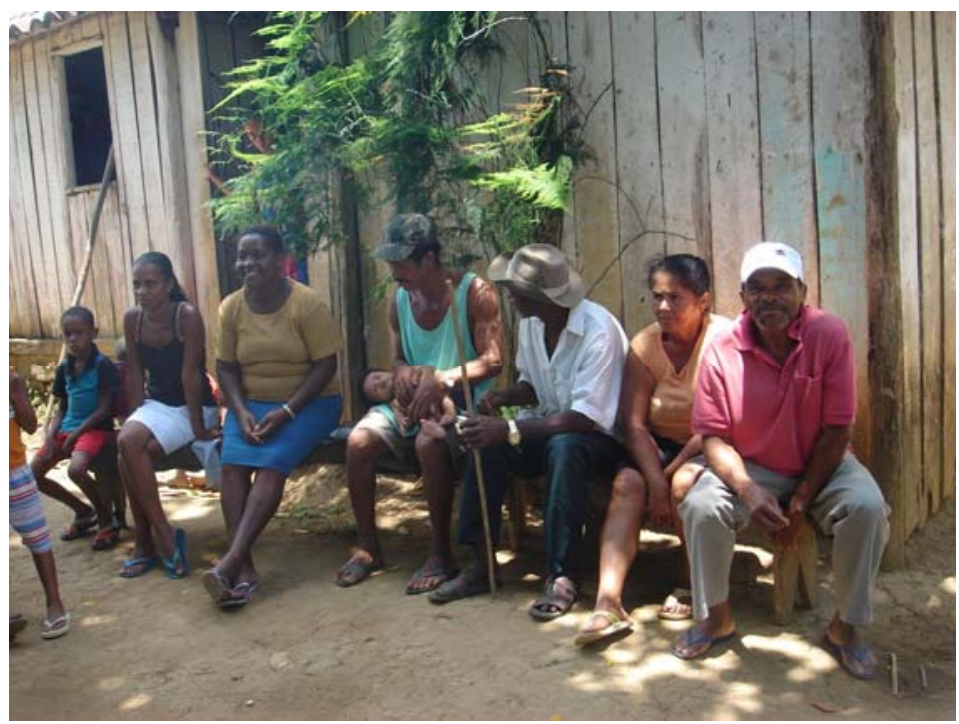

Figura 3 - Proprietários rurais de uma comunidade Quilombola. APA Itacaré Serra Grande (BA). Foto: Wildes Gomes de Campos.

\section{MÉTODOS}

A Área de Proteção Ambiental (APA) de Itacaré Serra Grande ocupa $28 \mathrm{~km}$ de extensão, com uma área total de 62.960 ha e abrangendo os municípios de llhéus, Uruçuca e Itacaré na região litorânea no Sul do Estado da Bahia (Figura 4).

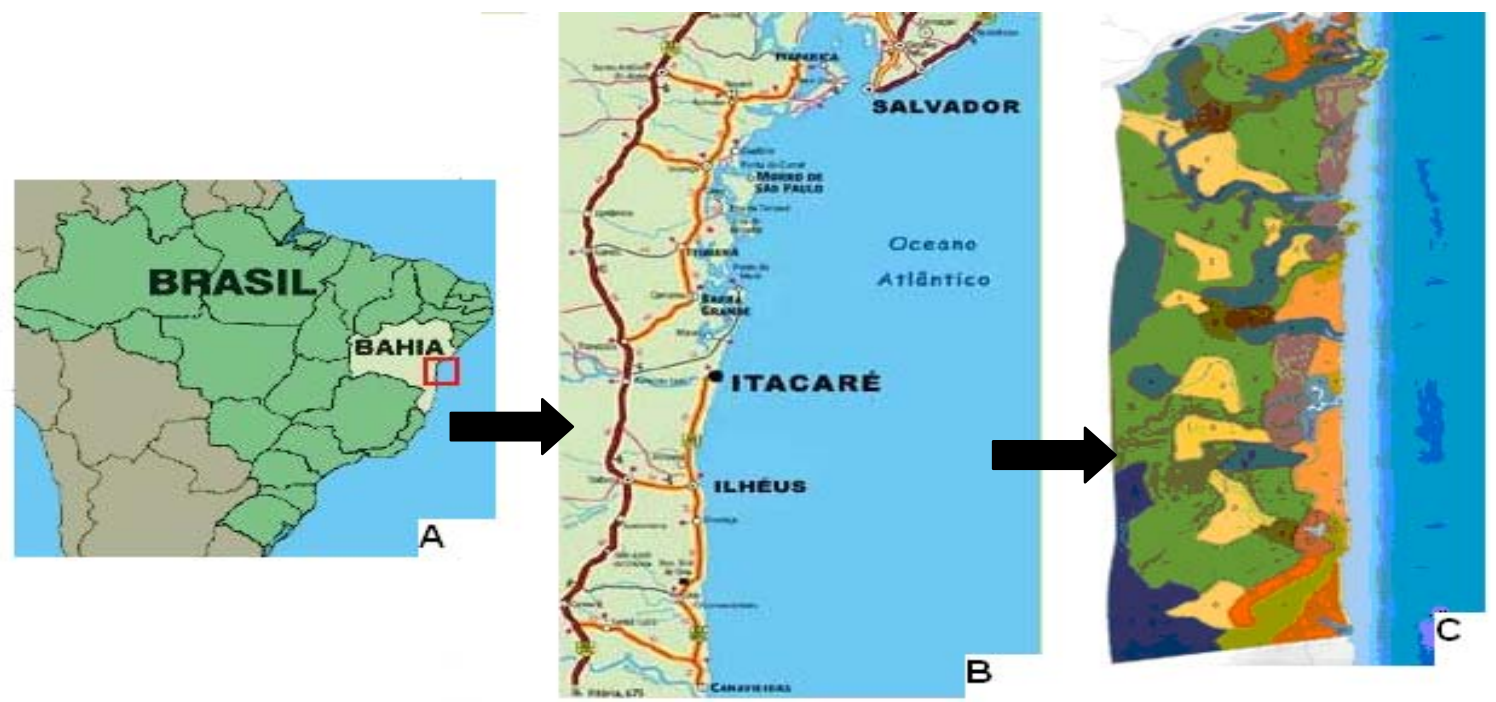

Figura 4- Localização geográfica da região de estudo. A: Bahia; B: Itacaré; C: APA de Itacaré Serra Grande. Fonte: A e B: itacaré.com; C: Google Maps. 
O trabalho de campo desenvolvido na região em 2008 objetivou realizar um diagnóstico para avaliar a possibilidade da criação de um fundo para pagamentos de serviços ambientais tendo o trade turístico como potencial doador e pequenos proprietários rurais vinculados a projetos socioambientais já em desenvolvimento, como beneficiários do mecanismo de pagamento. Foram entrevistados 37 proprietários rurais para calcular a renda agrária de cada propriedade e verificar o custo de oportunidade do uso da terra. A partir do custo de oportunidade ${ }^{2}$ seria possível estabelecer o valor do pagamento e o montante necessário para a composição do fundo. Com a finalidade de identificar a disponibilidade dos empreendedores locais a contribuir com o fundo, foram aplicados questionários de Valoração Contingente ${ }^{3}$ aos empreendedores turísticos locais, entre eles 29 pousadas, quatro hotéis, 11 restaurantes, três serviços turísticos; e a 98 turistas que visitavam a região de Itacaré. De acordo com o site de informações turisticas ${ }^{4}$ existem por volta de 96 empreendimentos e uma média de 80 mil turistas que visitam a região ao ano.

As entrevistas com os proprietários rurais (Figura 5) puderam levantar informações sobre cada propriedade e as atividades produtivas nelas desenvolvidas, focando suas receitas e despesas. Foi também observada a potencialidade das propriedades em dispor de serviços ambientais em função da área florestal preservada. Os questionários direcionados aos empreendedores e turistas, além de uma caracterização socioeconômica, abordaram aspectos da conservação ambiental e disponibilidade em contribuir financeiramente para a implementação do fundo.

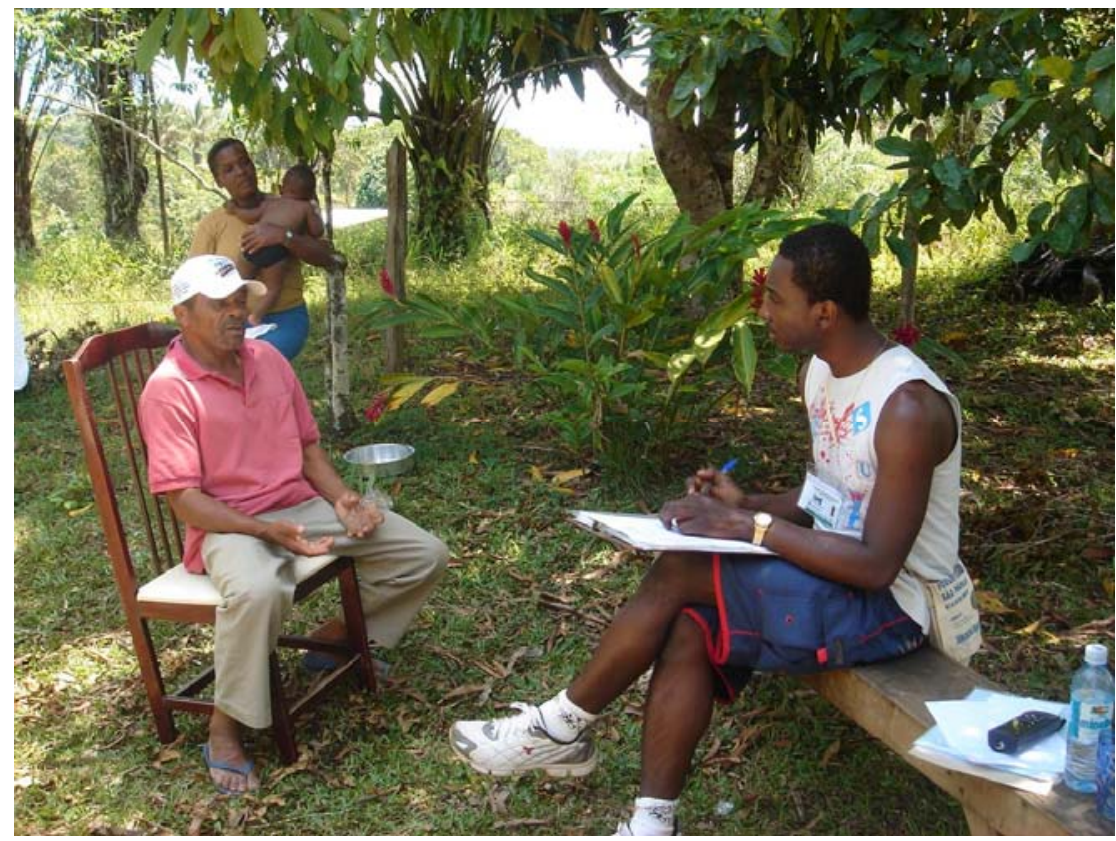

Figura 5- Entrevista com o proprietário rural. APA Itacaré Serra Grande (BA).

Foto: Wildes Gomes de Campos.

Os questionários foram elaborados e tabulados, conforme sugere Ditt et al., (2006), compostos de questões abertas, questões para ordenação (ranking) e ques- 
tões de alternativas. Os resultados das questões abertas, sendo qualitativos, foram agrupados em categorias de acordo com o tipo de resposta. As questões de ordenação foram estruturadas de acordo com o grau de importância em ordem crescente. Para as questões alternativas foram calculados os valores percentuais.

O questionário direcionado aos turistas foi utilizado também como ferramenta para identificar o perfil do turista frequentador da região, para através do cruzamento de dados e suas respectivas interpretações, possa-se observar se há um público turístico preferencial para otimizar esforços a fim da captação de recursos para a elaboração do fundo.

Para a valoração da renda agrária e análise do custo de oportunidade, os dados coletados com os pequenos proprietários rurais possibilitaram quantificar o valor monetário da produção agrícola. Os dados de cada atividade foram transformados em valores monetários anuais e foram somados utilizando a seguinte fórmula (FAO/ INCRA, 1995):

$$
R A=P B-C l-D+S b-S-I-J-R T
$$

onde: RA - renda agrária, PB - valor do produto bruto, $\mathbf{C l}$ - bens de consumo intermediários, D - depreciação do capital fixo, Sb - subsídios, S - salários, I - impostos, J juros e RT - renda da terra (arrendamentos).

Com aplicação do questionário aos empreendedores e turistas, objetivou-se identificar a disponibilidade de ambos os grupos a contribuir com o pagamento por serviços ambientais, e definir o valor médio da doação. Como existe uma sazonalidade de turistas (alta e baixa temporada), a maioria dos empreendedores sugeriu valores diários por turista, em vez de indicar uma taxa fixa de contribuição. Calculou-se a média dos valores das diárias de serviços (hospedagem, refeições e passeios turísticos) para chegar a uma taxa diária por turista. Como os turistas apresentaram diferentes formas para chegar ao valor de contribuição (taxa fixa por dia ou temporada; ou percentual dos gastos obtidos com a sua estada na região), a taxa estimada a pagar pelos turistas foi alcançada com a padronização dos valores sugeridos pelos entrevistados, transformando-os para valores em reais por pessoa/dia, e tirada a média desses valores.

\section{RESULTADOS}

Os 37 proprietários rurais entrevistados estão localizados em diferentes bairros e comunidades de Uruçuca e Itacaré. As atividades produtivas que os proprietários rurais realizam estão restritas ao cultivo em pequena escala de cacau, cravo, coco, mandioca, frutas e hortaliças e na criação de alguns animais, como galinhas, ovinos e suínos. Apesar de apresentarem remanescentes florestais, as matas das propriedades estão limitadas as áreas próximas de rios e nascentes.

A partir dos dados de renda agrária dos pequenos proprietários rurais, foi possível verificar que a maioria depende de rendas externas, seja por subsídios como bolsa-família, aposentadoria, salários, ou pelo programa do Txai-Social - de compen- 
sação por serviços ambientais instituído pelo resort Txai. A média de renda anual dos agricultores é de $R \$ 528,12$ por hectare, variando de - $R \$ 305,00$ a $R \$ 4.713,50$. Se desconsiderar a entrada de subsídios, a renda cai para $R \$ 214,00$ negativos, variando de - $\mathrm{R} \$ 1.372,75$ a $\mathrm{R} \$ 576,00$.

Os valores apresentados foram calculados de acordo com o levantamento das estimativas de renda agrária dos proprietários rurais. No entanto, os números negativos apontados são devidos à falta de informações obtidas sobre a produção rural, ou por desenvolverem agricultura de subsistência, o que fragilizou a precisão do estudo. Os proprietários entrevistados não possuem sistematização ou planejamento de suas culturas, o que os torna economicamente vulneráveis, pois não têm idéia dos custos e lucros da produção agrícola.

Em relação à preservação ambiental das propriedades, apesar das áreas florestais concentrarem-se nas Áreas de Preservação Permanente (APP), os proprietários mostraram-se dispostos a desenvolver negócios que sejam ecológica e economicamente viáveis, para não expandir as áreas de cultivo.

O perfil do turista da região foi caracterizado levantando dados de origem (Figura 6), faixa etária (Figura 7), grau de escolaridade (Figura 8) e renda familiar mensal.

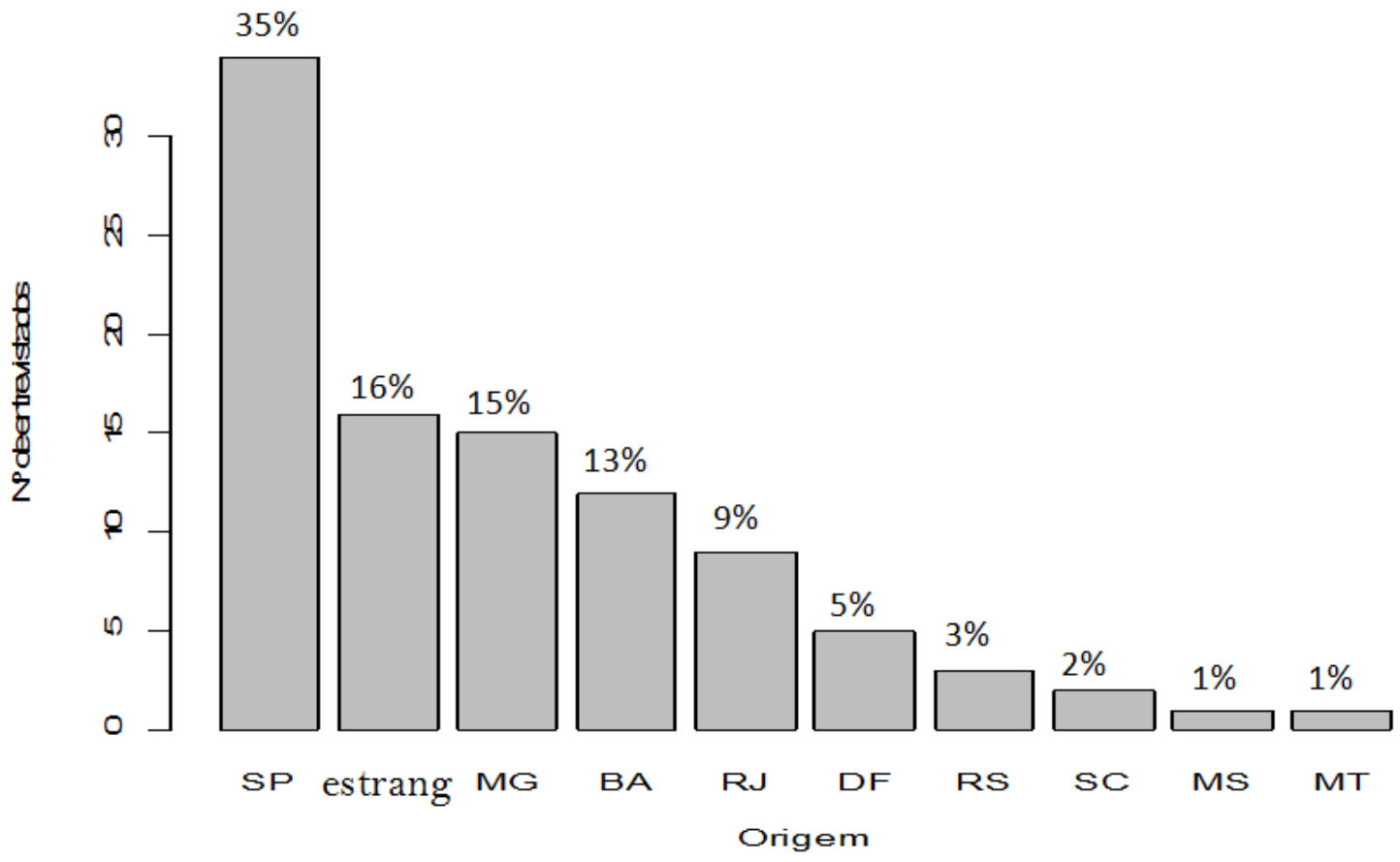

Figura 6 - Gráfico do número de entrevistados por origem.

Aplicando um teste de independência que utiliza a estatística de qui-quadrado, observou-se que o grau de escolaridade dos entrevistados não influencia na disponibilidade para contribuir com o fundo financeiro $\left(X^{2}=6,00 ; g l=3 ; p=0,11\right)$. O poder aquisitivo dos visitantes, que em sua maioria (68\%) são pessoas de classes média e mé- 


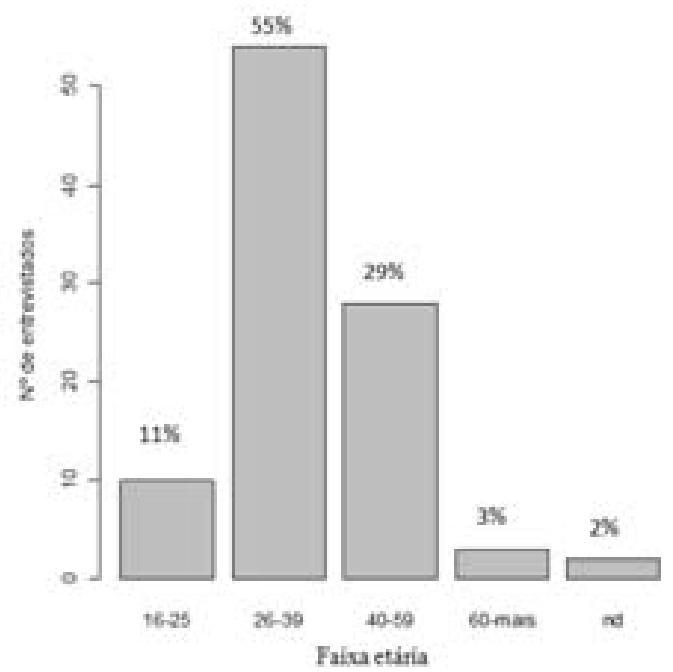

Figura 7 - Faixa etária dos turistas.

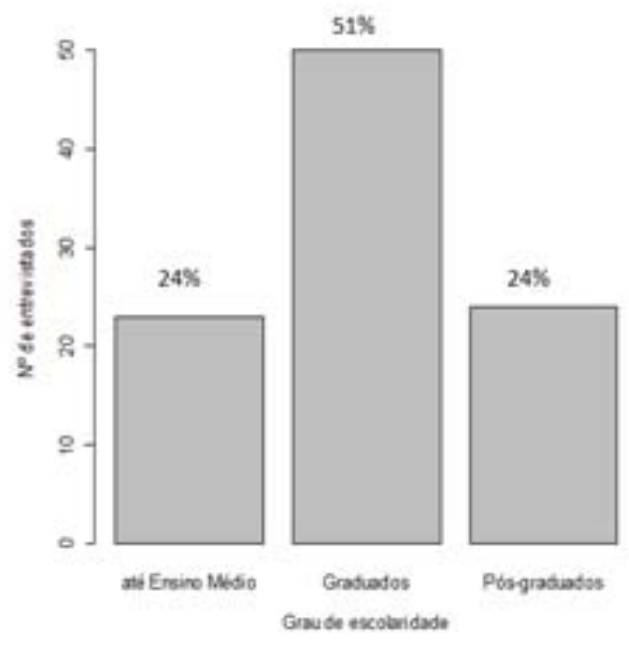

Figura 8 - Grau de escolaridade dos turistas

dia-alta, com renda superior a $\mathrm{R} \$ 3000,00$, também não interfere na disponibilidade para pagar dos entrevistados $\left(X^{2}=8,00 ; g l=6 ; p=0,23\right)$, o que significa que não existe um perfil específico de turista com potencial para contribuir com o fundo. A partir dos dados disponibilizados pelos empreendedores, cada turista gasta em média com alimentação e hospedagem na alta temporada $R \$ 122,00$ por dia, e $R \$ 94,00$ na baixa temporada.

A disponibilidade do turista entrevistado para contribuir com o fundo independe do seu engajamento junto às causas ambientais $\left(X^{2}=6,00 ; g l=5 ; p=0,30\right)$. No entanto, do número total de pesquisados, $76 \%$ declararam ter ações de conservação para com o meio ambiente, porém 40\% desse grupo acreditam que práticas cotidianas de limpeza (não jogar lixo no chão) devam ser consideradas como medidas de contribuição ambiental, enquanto $60 \%$ restantes desenvolvem ações como uso consciente de recursos e ações de impacto positivo para com o meio ambiente.

Entre os pesquisados, 94\% afirmaram que a região necessita de cuidados em relação ao meio ambiente, sendo que os fatores mais apontados referem-se às consequências do turismo (51\%) e à falta de estrutura básica, como saneamento e questões do lixo: 5\% não respondeu. De acordo com a declaração dos pesquisados, a responsabilidade em manter e preservar as áreas naturais é do governo (20\%), moradores locais (18\%), empreendedores turísticos (16\%), proprietários rurais (14\%), turistas (11\%), instituições de ensino (11\%) e, por fim, das organizações não governamentais $(10 \%)$.

Da disposição dos turistas em contribuir com recurso financeiro para pagamento de serviços ambientais, 56\% é favorável, mas muitos desses turistas ressaltam a necessidade de um projeto transparente em relação à captação e destinação de recursos e com monitoramento que envolva os doadores e beneficiários. Os turistas 
com disponibilidade para pagar sugeriram uma taxa média de $\mathrm{R} \$ 1,60$ por pessoa/dia, variando de $R \$ 0,50$ a $R \$ 15,00$.

Grande parte dos empreendedores turísticos locais (56\%) acha que não existe Ecoturismo na região e sim um turismo impactante sobre os atrativos naturais, e $44 \%$ acreditam que o Ecoturismo é importante para a região, mas que necessita de um ordenamento a fim de promover a conservação ambiental. Todos os empreendedores acham que a região de estudo estaria prejudicada sem os atrativos naturais, alterando as condições socioeconômicas da comunidade local. Também acreditam que é importante manter as áreas protegidas, e que a região necessita de cuidados com relação ao meio ambiente. No entanto, $15 \%$ dos empreendedores acham importante manter as áreas protegidas, mas não contribuem com ações de preservação. Os fatores que aparecem como de maior impacto na degradação da região estão relacionados à deficiência de estrutura básica à falta de programas de Educação Ambiental (58\%) e às consequências da demanda turística (42\%).

Vinte e três por cento dos empreendedores acham que a responsabilidade de manter e preservar as áreas naturais é do governo, seguido dos moradores locais (18\%), dos empreendedores turísticos (16\%), dos proprietários rurais (12\%), das instituições de ensino (11\%), das organizações não governamentais (11\%) e por fim, dos turistas (9\%). Noventa por cento dos empreendedores acham justo que os proprietários rurais recebam uma contribuição financeira para proteção das florestas na região, sendo que $85 \%$ deles estariam dispostos a pagar pela conservação ambiental. Quando questionados sobre como poderia ser a contribuição, 17\% dos empreendedores sugeriram que a doação deveria ser fixa e, em média, de $\mathrm{R} \$ 160,00$ por mês, com valores variando de $\mathrm{R} \$ 20,00$ a $\mathrm{R} \$ 415,00$.

Dos empreendedores entrevistados, $58 \%$ sugeriram que a taxa estabelecida esteja vinculada ao número de turistas atendidos em relação à alta e à baixa temporada. Outros recomendaram valores entre $R \$ 1,00$ e $R \$ 5,00$, cuja média é $R \$ 2,50$, e outros que o pagamento fosse uma porcentagem sobre o serviço prestado. Em média a taxa seria de $4 \%$. Assim, na alta temporada o empreendedor pagaria $\mathrm{R} \$ 2,80$ por turista/dia, e na baixa temporada, pagaria $\mathrm{R} \$ 2,10$, o que, numa média anual, seria de $\mathrm{R} \$ 2,50$.

\section{DISCUSSÃO}

As características da região em relação ao alto grau de biodiversidade e a presença de atrativos naturais, além de promoverem os serviços ambientais, permitem a continuidade das atividades turísticas, desde que ocorra o apoio dos empreendedores e turistas locais como doadores do fundo para pagamento por serviços ambientais. A pesquisa apontou que não há um público específico de turista disposto a dar sua contribuição, o que pode facilitar a implementação do mecanismo de PSA, abarcando os clientes de todo empreendimento, sem distinção.

Os agricultores a serem contemplados de início são os que aderirem voluntariamente ao programa, e que contemplem alguns critérios, como: a) uso sustentável da área; b) dependência econômica da propriedade; c) interesse na manutenção dos recursos naturais. O valor a ser pago às famílias deverá considerar um montante de re- 
embolso pelos serviços ambientais, a ser definido em levantamento futuro, e um montante suficiente para custos de manutenção da área, por exemplo, cercamento e plantio para reflorestamento.

O pagamento por serviços ambientais deve ser encarado como uma compensação pela manutenção de um recurso natural, e não como um mecanismo de redução de pobreza (PAGIOLA et al., 2005). Desse modo, os proprietários que receberem a compensação financeira têm a obrigação de manter os recursos naturais existentes na área, e o valor pode ser diferenciado para proprietários que aumentarem a área de cobertura florestal em sua propriedade. O dinheiro deve ser usado na construção de infraestrutura que auxilie o produtor na manutenção da área florestal, e também no investimento em atividades agrícolas que não agridam a natureza e possibilitem o aumento de renda familiar mensal. Para garantia dessas ações será necessária assessoria técnica aos proprietários, garantindo a eles conhecimento de sistemas produtivos sustentáveis e de técnicas de reflorestamento e de manejo do solo.

O estudo mostrou que apesar da disponibilidade dos empreendedores e turistas locais para participar do programa de pagamento por serviços ambientais, os pesquisados enfatizaram a necessidade de ações complementares que minimizem os impactos sobre os recursos naturais, tais como: saneamento básico, coleta seletiva de lixo e programas de Educação Ambiental a todos os envolvidos, apontando a necessidade de estruturação da gestão ambiental do município de Itacaré (Figura 9).

Tais ações podem ser otimizadas com a ampliação de parcerias entre a entidade executora do fundo e seus stakeholders, como entidades públicas e privadas, organizações não governamentais, universidades e demais instituições de ensino e com a própria comunidade local, através de um planejamento participativo e de corresponsabilidade pelas ações necessárias ao sucesso do programa de pagamento de serviços ambientais.

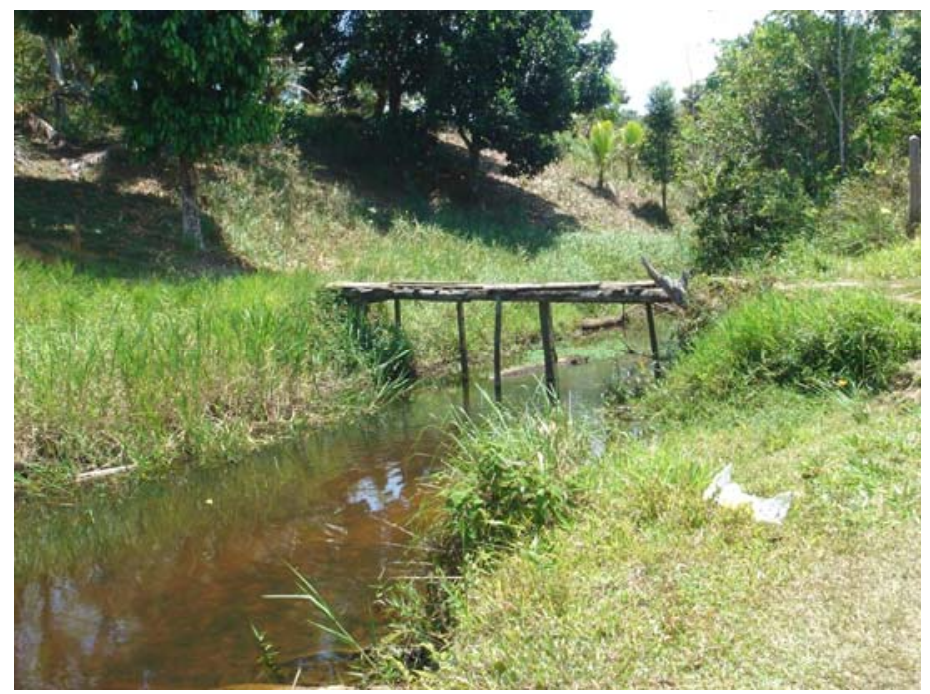

Figura 9 - Propriedade rural na APA Itacaré Serra Grande (BA) apontando a necessidade de estruturação da gestão ambiental, como a recuperação de Área de Proteção Ambiental (APP). Foto: Wildes Gomes de Campos. 


\section{CONSIDERAÇÕES FINAIS}

Conclui-se, portanto, que é viável a implementação de um fundo para pagamento de serviços ambientais na região da APA Itacaré Serra Grande, pois há disponibilidade para contribuição por parte dos empreendedores, turistas e dos proprietários rurais em potencializar a conservação das áreas florestais. No entanto, este mecanismo não é suficiente para garantir a sustentabilidade ambiental da região, necessitando de ações complementares com o desenvolvimento de políticas públicas voltadas para o setor.

Devido ao empobrecimento florestal verificado nas propriedades, sugere-se desenvolver um estudo de linha de base da biodiversidade, permitindo um diagnóstico atual das condições das áreas florestais de cada propriedade, para que se possa apontar os potenciais serviços ambientais a serem oferecidos por elas e realizar uma análise comparativa após serem efetuadas as intervenções nas propriedades.

Anteriormente a proposição de qualquer projeto com os proprietários abordados na região, há necessidade de desenvolver mecanismos de capacitação e acompanhamento em atividades que envolvam organização e controle de produção agrícola, ou seja, subsídios que proporcionem a autonomia dos proprietários rurais.

O valor a ser pago às famílias deverá considerar um montante de reembolso pelos serviços ambientais, a ser definido em levantamento futuro, e um montante suficiente para custos de manutenção da área, como, por exemplo, cercamento e plantio para reflorestamento.

\section{REFERÊNCIAS BIBLIOGRÁFICAS}

BRASIL. Lei no 9.985. Institui o Sistema Nacional de Unidades de Conservação. Diário Oficial, Brasília, 19/07/2000.

BRASIL. Grupo de Trabalho Interministerial MICT/MMA. Diretrizes para uma política nacional de Ecoturismo. Brasília, 1994.

DEAN, W.. A ferro e fogo: a história e a devastação da Mata Atlântica brasileira. São Paulo: Companhia das Letras, 1996.

DITT, E. H.; MANTOVANI, W.; VALLADARES-PADUA, C. B.; BASSI, C. Entrevistas e aplicação de questionários em trabalhos de conservação. In: CULLEN JR. L.; VALLADARES-PÁDUA, C.; RUDRAN, R. (orgs). Métodos de estudos em biología da conservação e manejo da vida silvestre. $-2^{\mathrm{a}}$ ed. - Curitiba: Ed. Universidade Federal do Paraná. p.631-646. 2006.

DE GROOT, R.S., WILSON, M.A.. BOUMANS, R.M.J. A typology for the classification, description, and valuation of ecosystem functions, goods and services. Ecological Economics..v. 41, no 3, pp. 393-408. Elsevier, 2002. 
FAO/INCRA. Análise Diagnóstico de Sistemas Agrários, 1995.

INSTITUTO FLORESTA VIVA. Apa Itacaré-Serra Grande: Revisão do Zoneamento Ecológico - Econômico. Responsável técnico: Joel M. Berbert de Carvalho. 2004.

INSTITUTO FLORESTA VIVA. Porto Sul: Estudo ambiental preliminar do sítio selecionado para locação de porto e aeroporto no Sul da Bahia. Responsável técnico: Joel M. Berbert de Carvalho. 2008.

LAYRARGUES, P.P. A função social do Ecoturismo. Boletim Técnico do Senac. Volume 30, no 1. jan/abr. p. 39-45, 2004.

NEIMAN, Z. A Educação Ambiental através do contato dirigido com a natureza. 2007. Tese (Doutorado em Psicologia) - Instituto de Psicologia -Universidade de São Paulo, São Paulo, 2007.

MICOL, L.; ANDRADE, J.; BORNER, J. Redução das emissões do desmatamento e da degradação florestal (REDD): potencial de aplicação no Estado de Mato Grosso. Cuiabá: Instituto Socioambiental, The Nature Conservancy Brazil, 2008.

PADUA, S. M.; LOPATA, J.;SWAMY, S.L.N.; RAVENDRA, V.. Ecoturismo e Conservação da Natureza. In: ROURE, M.; PÁDUA, S. M. (orgs). Empreendedores sociais em ação. São Paulo: Cultura Editores Associados. p.25-32. 2001.

PAGIOLA, S.; ARCENAS, A.; PLATAIS, G.. Can Payments for Environmental Services Help Reduce Poverty? An Exploration of the Issues and the Evidence to Date from Latin America. World Development. p.237-253. 2005.

SEROA da MOTTA, R. Economia Ambiental. Rio de Janeiro: FGV Editora, 2006.

VASQUES, C. (). Itacaré Instituto de Turismo. São Paulo: HVS International, 2005.

WUNDER, SVEN, coord. Pagamentos por serviços ambientais: perspectivas para a Amazônia Legal. Brasília: MMA, 2008. 136 p.

\section{Notas}

${ }^{1}$ Este trabalho foi desenvolvido como produto da disciplina Resolução de Desafios, que faz parte do Programa de Mestrado em Conservação Ambiental e Sustentabilidade do Instituto de Pesquisas Ecológicas - IPÊ. $2^{\circ}$ semestre/2008. 
${ }^{2}$ O método do custo de oportunidade não valora diretamente o recurso natural, mas estima o custo para preservá-lo pela não realização de uma atividade econômica concorrente (SEROA da MOTTA, 2006).

${ }^{3}$ O Método de Valoração Contingente utiliza dois indicadores de valor: disposição a pagar (DAP) e disposição a aceitar (DAA), ou seja, quanto os indivíduos estariam dispostos a pagar para obter uma melhoria de bem-estar, ou quanto estariam dispostos a aceitar como compensação para uma perda de bem-estar (SEROA da MOTTA, 2006).

${ }^{4}$ http://www.itacare.com

\section{AGRADECIMENTOS}

Aos docentes e colegas da Escola Superior de Conservação Ambiental e Sustentabilidade - ESCAS - IPÊ.

Aos colaboradores do Instituto Floresta Viva (BA), em especial ao Rui Barbosa Rocha e à Cinira de A. F. Fernandes.

Marco Aurélio Pereira: Escola Superior de Conservação Ambiental e Sustentabilidade - ESCAS.- Instituto de Pesquisas Ecológicas (IPÊ)

Email: marcoaurelio8@terra.com.br

Link para o currículo Lattes: http://lattes.cnpq.br/5770483285623060

Wildes Gomes de Campos: Escola Superior de Conservação Ambiental e Sustentabilidade - ESCAS - Instituto de Pesquisas Ecológicas (IPÊ)

Email: wildes@kbonet.com.br

Link para o currículo Lattes: http://lattes.cnpq.br/6692000280387560

Data de submissão: 27 de junho de 2009

Data do aceite: 29 de agosto de 2009 